\title{
Kestirimci Bakım İçin Döner Mekanizma Bozulma Eğrisinin Tanımlanması
}

\author{
Oğuz Bektaş ${ }^{1 *}$ \\ 1 İstanbul Medeniyet Üniversitesi, Mühendislik ve Doğa Bilimleri Fakültesi, İstanbul, Türkiye (ORCID: 0000-0003-3687-3703) \\ PhD: University of Warwick, MSc: Queen Mary University of London
}

(İlk Geliş Tarihi 24 Mart 2020 ve Kabul Tarihi 16 Haziran 2020)

(DOI: $10.31590 /$ ejosat.708257)

\begin{abstract}
ATIF/REFERENCE: Bektaş, O. (2020). Kestirimci Bakım İçin Döner Mekanizma Bozulma Eğrisinin Tanımlanması. Avrupa Bilim ve Teknoloji Dergisi, (19), 420-428.

Öz

Sistem durum verilerinin değerlendirilmesi ve teşhisi, havacılık gibi gelişen sektörler için önem kazanmaya başlayan ve kestirimci bakım konusunda ilerleme sağlayan bir alandır. Döner mekanizma sistemlerinin daha güvenilir olması talebiyle birlikte; sistemlerin karmaşıklığının artması bakım uygulamalarındaki operasyonel zorlukları büyük ölçüde artırmıştır. Bununla birlikte; modern sistemlerde varlıkları giderek artan durum izleme sensörleri bu problem için bir yardım sağlayabilir. Kestirimci bakım yöntemlerinin geliştirilmesi aktif bir araştırma alanı olup, başarılı modellerin geliştirilmesi için, kullanım ömrü boyunca veri toplanması gerekmektedir. Bu çalışmada, ilk olarak döner mekanizma sistemleri için kestirimci bakımın bir özeti sunulmuş, sonrasında bozulma aşamalarının tanımlanması için Welch yöntemi ve Fourier dönüşümleri ile spektrogram hesaplamaları işlenmiştir. Önerilen uygulama, döner mekanizmaların bozulma analizi için PRONOSTIA deneysel platformundan elde edilen bozulma veri seti kullanılarak test edilmiştir. Çalışma, döner mekanizma arıza analizi, tahmini ve sağlık yönetim teknolojilerinin uygulanmasında kritik bir ön başlangıç adımdır. Uygulama ve sonuçlar, önerilen çalışmanın durum verileri kullanılarak sistem düzeyinde bir modellemeye uygulanabileceğini ve çok aşamalı uzun süreli döngülerde sistemin aşınma seviyesini etkin bir şekilde tahmin edebildiğini göstermektedir.
\end{abstract}

\section{Identification of Rotating Machinery Degradation Curve for Predictive Maintenance}

\begin{abstract}
Health assessment and diagnostics of condition monitoring data is an area that is becoming increasingly important to the advancing industries such as aerospace and making progress in predictive maintenance. Increasing complexity of systems, along with the demand for more reliable rotating mechanism system, has dramatically increased operational difficulties in maintenance applications. However; condition monitoring sensors, the presence of which is increasing in modern systems, can provide an aid to this problem. The development of predictive maintenance methods is an active research area, and it is necessary to monitor data throughout the life cycle to develop successful models. In this study, firstly, a summary of predictive maintenance for rotating mechanism systems is presented, then, the Welch's method with Fourier transforms is processed to define the stages of degradation. The proposed model has been tested using PRONOSTIA data set from an experimental platform for accelerated degradation tests. The study is a critical preliminary step in the implementation of rotating mechanism failure analysis, estimation and health management technologies. Implementation and results show that the proposed study can be applied to a system-level setting and can effectively predict the wear level of the system in multistage long-term cycles.
\end{abstract}

Keywords: Aerospace, Degradation, Welch's Method, Fourier Transforms, Degradation Predictive Maintenance, Rotating Machinery.

\footnotetext{
* Sorumlu Yazar: İstanbul Medeniyet Üniversitesi, Mühendislik ve Doğa Bilimleri Fakültesi, İstanbul, Türkiye (ORCID: 0000-0003-3687-3703), oguz.bektas@medeniyet.edu.tr, oguz.bektas@warwickgrad.net
} 


\section{Giriş}

Günümüzde artan endüstrileşme, çeşitli ve karmaşık hale gelen sistemler, zamanla çoğalan alternatif yöntemler ve önem kazanan karar verme süreçleri, "kestirimci bakım" uygulamalarını ilgi çeken bir disiplin haline getirmektedir. Teknolojinin gün geçtikçe gelişmesi ve ilerlemesi, bakım giderlerini azaltma ihtiyacını zorunlu hale getirip, otomasyon ağırlıklı uygulamaların artmasına olanak sağlamıştır. Bu uygulamalar temel olarak üç unsurla ilgilidir: verilerin toplanması, işlenmesi ve öznitelik seçimi. Verilerin elde edilmesi amacıyla döner mekanizmalar, dişliler ve rotorlar gibi makinelerin durum verilerinin izlenmesi son yıllarda artan bir ilgi görmüştür (Lei Y. , Lin, He, \& Zuo, 2013; Lei Y. , Lin, Zuo, \& He, 2014). Bu yönelimin temel nedenini, makinelerin sürdürülebilirliği, güvenilirliği, kullanılabilirliği ve üretkenliğini artırmadaki önem oluşturmaktadır. Bu konudaki bir diğer neden ise otomatik kontrol sistemlerinin alg1 aracıları olan sensör (ya da algılayıcı) sistemlerin kullanımının artması ve kolaylaşmasıdır. Bu sensörler, algılayıcıları vasıtasıyla, organik duyu sistemlerine benzer biçimde, sistemlerdeki titreşim, hız, sıcaklık, basınç ve benzeri değerleri istenilen süreler içinde ölçebilmektedir. Dolayısıyla, günümüzde yeni bilgiler sürekli olarak izlenmekte, depolanmakta ve işlenmektir. Ayrıca, elde edilen verilerin gün geçtikçe katlanarak arttığına tanık olunmaktadır (Mayer-Schönberger \& Cukier, 2013). Özellikle, IBM'in her 18 ayda bir elde edilen verilerin iki katına çıktığını tahmin etmesi dikkate değer bir noktadır (Mills, et al., 2012). Bu gelişmenin bir sonucu olarak, "Büyük Veri" ve "Nesnelerin İnterneti" konusundaki uygulamalar kayda değer bir şekilde artmış ve güncel bilgilerin gelmesiyle izlenen verilerin daha detaylı olarak analiz edilebilme imkânı ortaya çıkmıştır. Bu büyük miktarda verinin, hızlı bir biçimde kestirimci bakım için eyleme dönüştürülebilir bilgiye çevrilmesi kilit bir görevdir.

Kestirimci bakım, sistemlerden alınan durum verilerine dayanarak, içerdikleri donanımların öngörülen kullanışlı ömrünü planlayarak ve bozulma riskini minimize ederek, sistemin hizmet süresini en üst seviyeye çıkarılmasını hedefler (Öztanır, 2018). Kestirimci bakım için kullanılan yöntemlerle, periyodik olarak çalışan sistemlerden elde edilen veriler izlenerek, operasyon boyunca ölçümler alınır ve bu ölçümlerle veri analizi yapılır (Yaman \& Karadayı, 2014). Kestirimci bakım, yaygın olarak kullanıldığı döner mekanizma parçalarında ise beklenmedik arıza ve kazalardan kaçınmak için rulman ve yatak kusurlarını mümkün olduğunca erken tespit etmeyi hedefler (Heng, Zhang, Tan, C., \& Mathew, 2009). Özellikle bu kısımlarım hizmet sürelerinin hesap edilmeleri bakım planları için öneme sahip olmakla birlikte, aksama süresi, maliyetler ve güvenlik risklerini azaltma konusunda gereklidir. Şekil 1'de görüldügü üzere, kestirimci bakım; verilerin toplanması ve işlenmesi, öznitelik seçme ve tanımlama, sistem tahmin ve diagnostiklerinin (tanı) karar desteğine iletilme süreçlerini içerir.

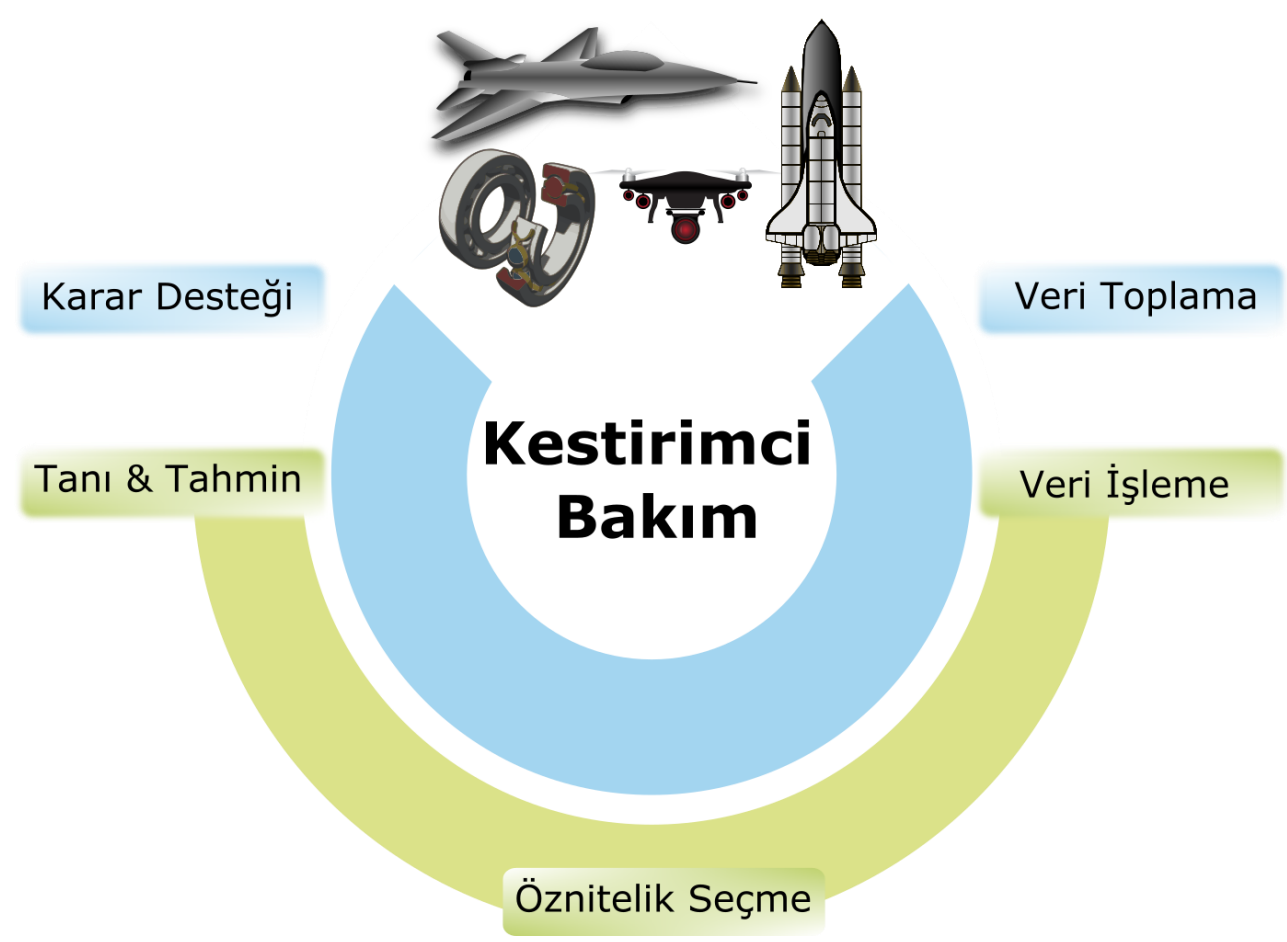

Şekil 1 Kestirimci Bakım Uygulamaları

Her ne kadar bu süreçler birbiriyle ileri derecede ilişkili olarak görülse de her bir süreç kendi içerisinde tasarlanmalı ve takip edecek olan sürece faydalı bilgi göndermelidir. Bu araştırmada, PRONOSTIA platformundan toplanan verilerin işlenmesi ve öznitelik seçimiyle bozulma aşamalarının tanımlanması amaçlanmıştır. Titreşim verilerinden hedef tanımlaması sağlayabilmek için, verilerin sebep-sonuç biçiminde etiketlenmesinden yararlanılarak kestirimci bakım için giriş verişi temin edilecektir. Böylece, tahmin ve diagnostik uygulamaları ile ilgili çıkarımlar yapabilmek için bozulma eğrisi elde edilebilecektir. 
Bu çalışma dört bölümden oluşmaktadır. İkinci bölüm, kullanılan materyal ve metotla ile ilgili çalışmalar ve literatür incelenecektir. Takip eden bölüm ise PRONOSTIA veri setine metodun uygulanmasını ve elde edilen sonuçların analizini içermektedir. Son kısım ise önerilen çalışmanın irdelenmesi, uygulanabilirliği, kısıtları ve potansiyel kullanım önerilerini içermektedir.

\section{Materyal ve Metot}

\subsection{Veri Seti}

Çalışmada kullanılan veriler döner mekanizmaların hızlandırılmış ömür testleri aracılığıyla sağlanmıştır. Bu deneyler, "FrancheComté Electronics Mechanics Thermal Science and Optics - Sciences and Technologies” Enstitüsü (Besançon, Fransa) tarafından sağlanmıştır (Patrick, Rafael, \& Kamal, 2012). Bu veri seti ayrıca, 2012 yılında Denver'da gerçekleşen "Prognostics and Health Management" konferansında Prognostics Challenge Veri Seti (PHM2012) olarak verilmiştir. Veri setini oluşturmak için kullanılan PRONOSTIA platformu, döner mekanizmaların arıza tespit, teşhis ve tahminleri için ortaya konacak uygulamaları test etmeye ve doğrulamaya yönelik dizayn edilmiş bir deney altyapısıdır. Yukarıda belirtilen enstitüde tasarlanmış olup, temel amacı döner mekanizmaların çalışma ömürleri ve bozulma karakteristiklerini gerçek titreşim verileri ile sağlamaktır (Patrick, Rafael, \& Kamal, 2012). Veri setlerine göre, titreşim sinyalini ivme genliği bozulma eşiğini aştığında, yatağın arızası olduğu kabul edilir. 17 farklı döner mekanizma (rulman), Tablo 1'de gösterildiği üzere üç farklı çalışma koşulunda test edilmiştir. Döner mekanizmaların altısı, 1-1, 1-2, 21, 2-2, 3-1, 3-2, öğrenme verisidir ve geri kalan 11 veri test için kullanılmıştır. Devam eden bölümde titreşim sinyalinin ivmelenmesi kullanılarak bozulma eğrisi için modelleme sunulacaktır. Bu amaçla sağlıklı durumdan arızaya kadar tüm operasyon aşamalarını ve bozulma karakteristiğini gösterdiği için Öğrenme Verisi DM 1-1 kullanılmıştır.

Tablo 1. Döner Mekanizma (DM) Çalışma Koşulları (Patrick, Rafael, \& Kamal, 2012; Hong, Zhou, Zio, \& Hong, 2014)

\begin{tabular}{|c|c|c|c|c|}
\hline Veri Seti & $\begin{array}{c}\text { Ÿ̈k } \\
(N)\end{array}$ & $\begin{array}{c}\text { Hiz } \\
\text { Dakikadaki } \\
\text { Devir Sayısı }\end{array}$ & $\begin{array}{c}\text { Öğrenme } \\
\text { Verileri }\end{array}$ & $\begin{array}{c}\text { Test } \\
\text { Verileri }\end{array}$ \\
\hline Veri Seti 1 & 4000 & 1800 & $\begin{array}{l}D M 1-1 \\
D M 1-2\end{array}$ & $\begin{array}{l}D M \quad 1-3 \\
D M ~ 1-4 \\
D M ~ 1-5 \\
D M ~ 1-6 \\
D M ~ 1-7\end{array}$ \\
\hline Veri Seti 2 & 4200 & 1650 & $\begin{array}{l}D M 2-1 \\
D M 2-2\end{array}$ & $\begin{array}{l}D M 2-3 \\
D M 2-4 \\
D M 2-5 \\
D M 2-6 \\
D M 2-7\end{array}$ \\
\hline Veri Seti 3 & 5000 & 1500 & $\begin{array}{l}D M 3-1 \\
D M 3-2\end{array}$ & DM 3-3 \\
\hline
\end{tabular}

\subsection{Yöntem}

Çalışmanın takip edeceği aşamalar, Şekil 2'de gösterilmiştir. Bu adımlar bozulma aşamalarının tanımlanması açısından kronolojik olarak kabul edilebilir. İlk adım kullanılan veri setini temsil etmektedir. Sonrasındaki adımlar tespit esas olarak hem titreşim verilerinin durumunun işlenmesi hem de işlenen verilerin analizi yapılarak bozulma eğrisini çıkarmaya odaklanır.

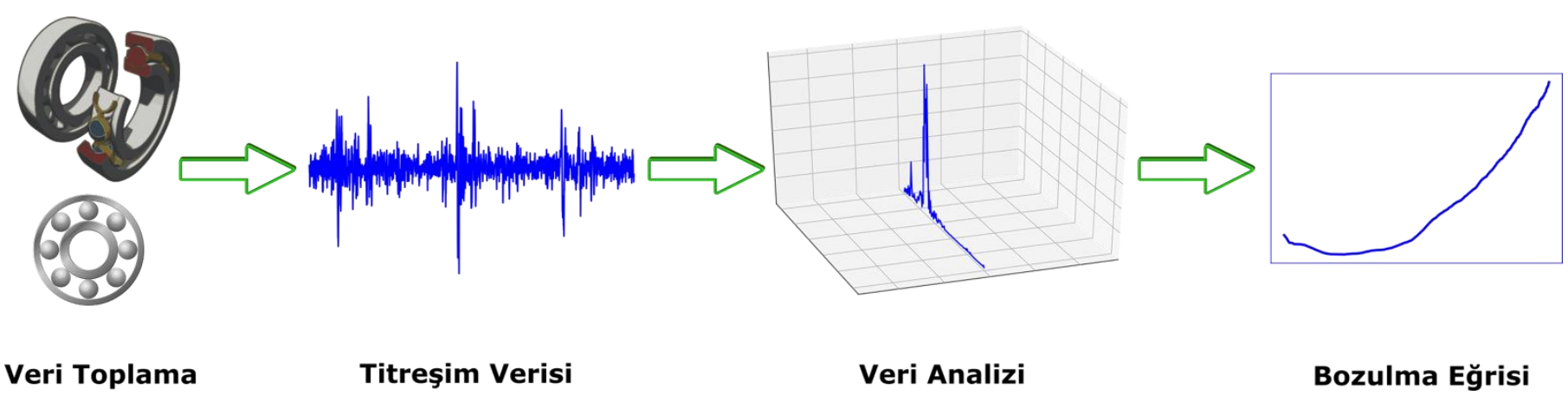

Şekil 2 Mekanizma Bozulmasının Tanımlanmasına Genel Bakış

DM 1-1 yedi milyonun üzerinde veri noktasından oluşmasına rağmen; bu veriler 2803 alt veri setine toplanmıştır. Çalışma öncelikle bu alt veri setlerini içe aktarma ile başlar ve çıkarılan her kümeye Welch metodu (ayrıca periodogram yöntemi olarak da bilinir) 


\section{European Journal of Science and Technology}

uygulanır (Welch, 1967). Böylece her yeni alt veri seti çıkarılıp titreşim arttıkça hesaplanan ve büyüklüğü artan hızlı fourier dönüşüm (fast Fourier transform - FFT) sonuçlarıyla gözlemlenebilmesi hedeflenmiştir. Fourier analizi, bir sinyali genellikle zaman veya uzay gibi orijinal alanından alarak frekans alanındaki bir gösterime dönüştürür (ve ya bunun tersi yönde işler).

$x_{0}, \ldots, x_{N-1}$ olarak kabul edildiğinde Fourier dönüşüm Denk. 1'de olduğu üzere tanımlanır (Welch, 1967):

$$
X_{f}=\sum_{n=0}^{N-1} x_{n} e^{-\frac{i 2 \pi}{N} f n}, f=0, \ldots, N-1
$$

Bir güç spektrumu, $P_{x x}(f)$, bu formül kullanılarak Denk. 2'de olan biçimde bulunur.

$$
P_{x x}(f)=\frac{1}{N}\left|X_{f}\right|^{2}=\frac{1}{N}\left|\sum_{n=0}^{N-1} x_{n} e^{-\frac{i 2 \pi}{N} f n}\right|^{2}
$$

Welch'in güç spektrumlarını tahmin etme yöntemi yukardaki formülü kullanarak, zaman sinyalini ardışık bloklara bölerek, her blok için periodogram oluşturarak ve ortalamayı alarak çalışır (Welch, 1967; Smith, 2011). Yukarıda belirtilen $x$ sinyali pencereli ve dolgulu bir çerçeve olarak Denk. 3'deki hali ile belirtilir.

$$
N=L+D(K-1)
$$

Burada $K$ toplam blok sayısını, $L$ blok uzunluğunu ve $D$ blok başlangıçlarının birbirine olan mesafesini göstermektedir. Böylece bloklar Denk. 4'de olan biçimde ifade edilir.

$$
x_{k}(j)=x(j+D(k-1)), j \in\{0,1, \ldots, L-1\}, k=1, \ldots, K
$$

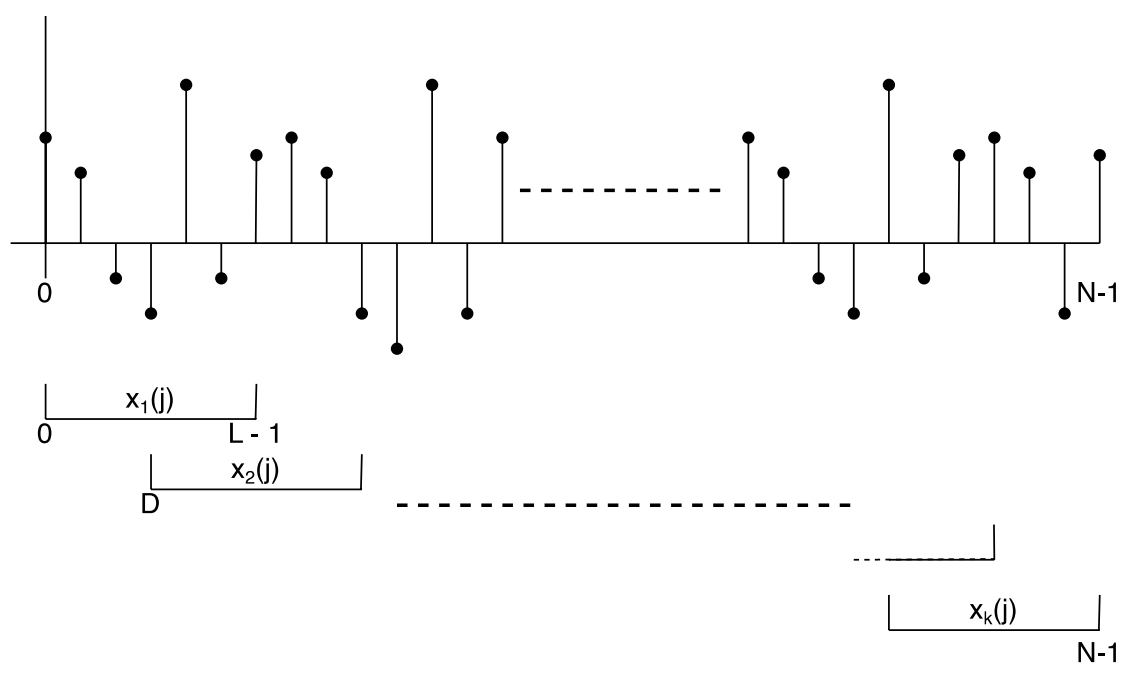

Şekil 3 Kayıt Bölümlemesi (Segment gösterimi)

Zaman serilerinin bu şekilde bölümlere (segmentlere) ayrılması Şekil 3 'te gösterilmiştir. Uygulamada $L$ blok uzunluğu 256 adım ve $D$ blok mesafesi ise bunun yarısı olacak şekilde ayarlanmıştır. Welch metodu bu segmentleri ağırlık katsayısıyla çarparak kullandığı için Denk. 5'de gösterilen ifade elde edilir

$$
x_{k}(j) w(j)
$$

Devamında, bu diziler periodogram yöntemine uygulandığında, "modifiye” periodogramı elde edilir ve Denk. 6'da sunulan eşitlik ile verilir. 


$$
\tilde{P}_{x x}^{(k)}(f)=\frac{1}{L U}\left|\sum_{j=0}^{L-1} x_{k}(j) w(j) e^{-\frac{i 2 \pi}{N} f n}\right|^{2}
$$

Öncesinde olduğu üzere Welch güç spektral yoğunluğu tahmini Denk. 7'de olan şekilde temin edilir.

$$
U=\frac{1}{L} \sum_{j=0}^{L-1} w^{2}(j)
$$

Burada $U$ pencere fonksiyonu içerisinde güç için normalleştirme faktörünü temsil eder.

Bu gösterim süre boyunca ortalama bir periodogramdır. $w$ dikdörtgen pencere olduğu var sayıldığında, periodogramlar üst üste gelmeyen ardışık verilerin bloklarından oluşmaktadır. Son olarak, Welch tahmini, $P_{x x}^{W}(f)$, modifiye edilmiş bu periodogramların ortalamasını alır (bknz Denk. 8).

$$
P_{x x}^{W}(f)=\frac{1}{K} \sum_{i=1}^{K} \tilde{P}_{x x}^{(i)}(f)
$$

\section{Araştırma Sonuçları ve Tartışma}

$\mathrm{Bu}$ bölümde yukarıda verilen yöntemin titreşim verisine uygulanmasıly elde edilen bulgular grafikler ile görselleştirilecektir. Bu amaçla, analizleri ve gösterimleri gerçekleştirmek için Python 3 kullanılmıştır. Yöntem her alt veriye sırasıyla uygulanması neticesinde alınan sonuçların büyüklüğünün arttığı gözlemlenmektedir. Bu sonuca ulaşmak için ilk önce veri setleri tek bir grafikte toplanmış ve titreşim ivmesinin zamanla arttığı gösterilmiştir (bknz Şekil 4-a). Zaman alanındaki titreşim sinyalleri, sinyal dürtüsellikte gittikçe artan bir eğilim gösterir. Sistemlerin bozulması (degradation) exponansiyel olarak arttığı için Şekil 4-b’deki bulunan artış (renk specktrumundaki artışla birlikte düşünülmelidir) döner mekanizmada sistem arızasının olduğunu göstermektedir.

Tek renkli gösterim bozulma aşamalarını tam olarak gösteremeyeceğinden, Şekil 4-b'de bu aşamaları temsil etmesi amacıyla renk spektrumu (Wistia - Python 3 matplotlib.cm.get_cmap) verilmiştir. Burada ve devam eden görsellerde renk haritası kullanılmasının arkasındaki temel amaç, veri kümesinin gösterimi için 3B renk alanında ve kabul edilebilecek '0-1' şiddet aralığında iyi bir temsil bulunmasidir.

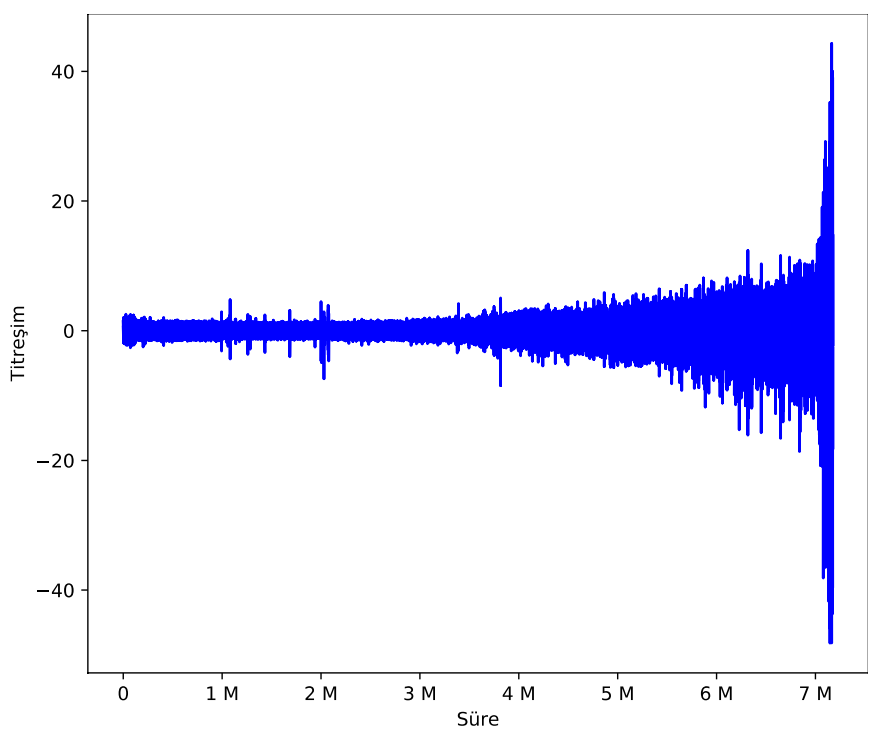

Şekil 4- a) İ̧̧lenmemiş Veri

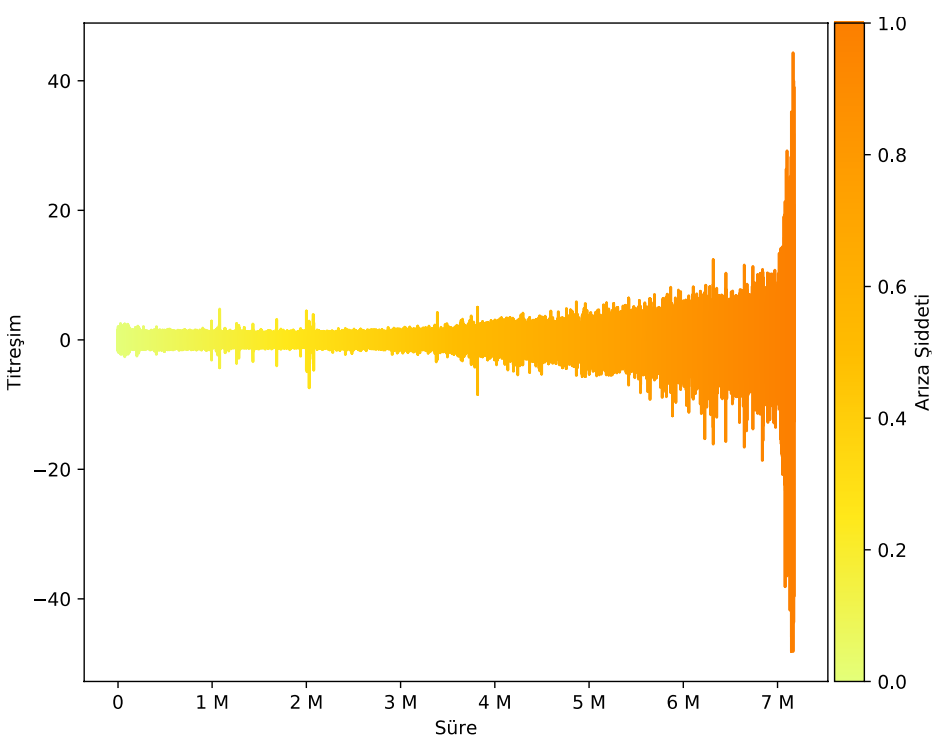

Şekil 4- b) Renk Ayrımı ile Gösterim

Burada gösterilen verilere Welch yöntemi uygulandığında bozulmanın tanımı için güçlü bir gösterim elde edilecektir. 3 boyutlu olarak her bir alt veri setinden alınan sonuçlar, değişiklikleri zaman içinde temsil edecek şekilde Şekil 5-a'da gösterilmiştir. Fakat önceki şekillerde görüldüğü üzere sistem operasyonunun sonuna yaklaşıldıkça güç spektral yoğunluğu oldukça artmıştır. Degradasyonun daha iyi temsil edilmesi için Şekil 5-b'de bu son kısımlar çıkartılarak kısmi olarak sonuçlar sunulmuştur. Burada görüleceği üzere her alt veriden elde edilen sonuçlar gittikçe artan değerler vermektedir ve bozulmanın tanımlanması için potansiyel teşkil etmektedir. 


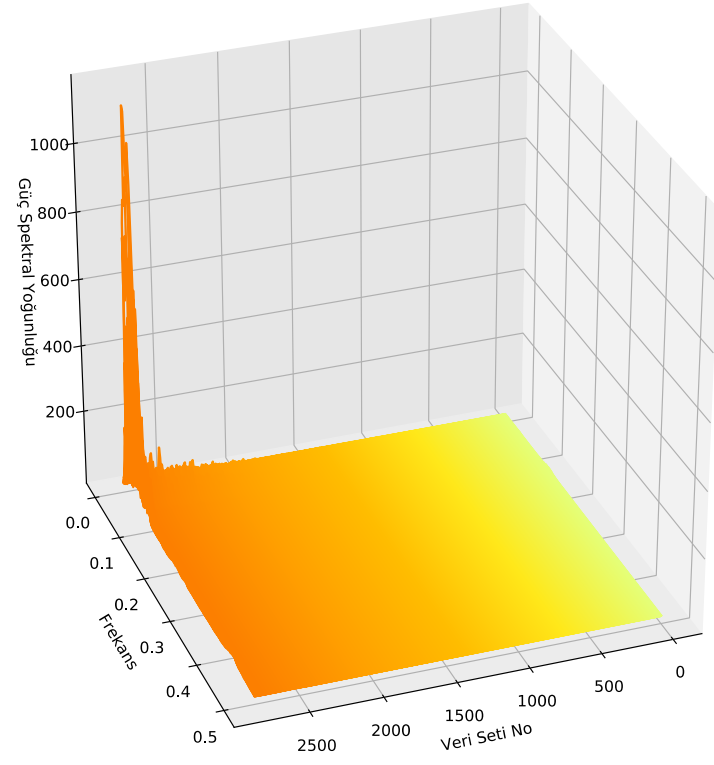

Şekil 5- a) Güç Spektral Yoğunluğu

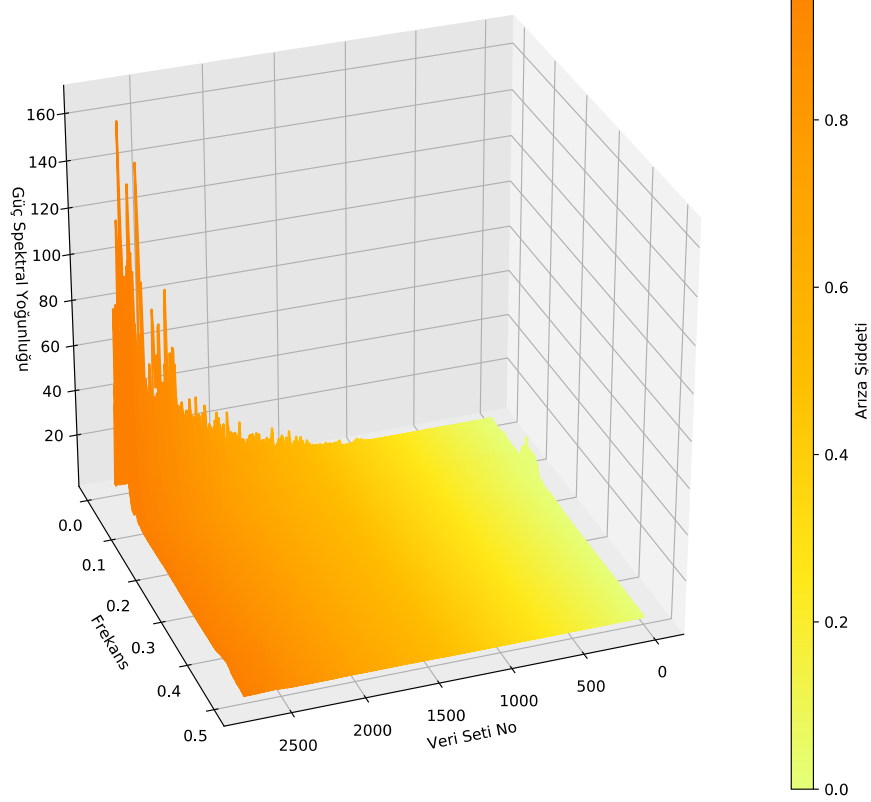

Şekil 5- b) Güç Spektral Yoğunluğu (Klsmi)

Şekil 5-a ve b'de Welch tahmin değerinin zamanla artarak değişimi, titreşim verisi işleme yönteminin belirgin olarak fayda sağladığını ve bozulmanın analizi için kullanışlı olduğunu göstermektedir. Eşik değeri elde edilen bu sonuçlara göre belirlenebilir ve bozulmanın aşama aşama bu değere yaklaştığı söylenebilir. Özellikle, Şekil 5-b'de görüldüğü üzere kısmen daha stabil olan bozulmanın operasyonun son aşamalarında hızla arttığı (bknz Şekil 5-a) ve yıkımsal bir hata seviyesine girdiği söylenebilir.

Alt veri setlerinin yoğunluğundan (toplamda 2803 veri dosyası vardır) alınan sonuçların yukarıdaki görsellerde tekil olarak incelenmesi görece daha zordur. Bu nedenle, ortalama her 300 veri setinden bir tanesinin sonuçları verilecek şekilde alınan bulgular Şekil 6'da verilmiştir.
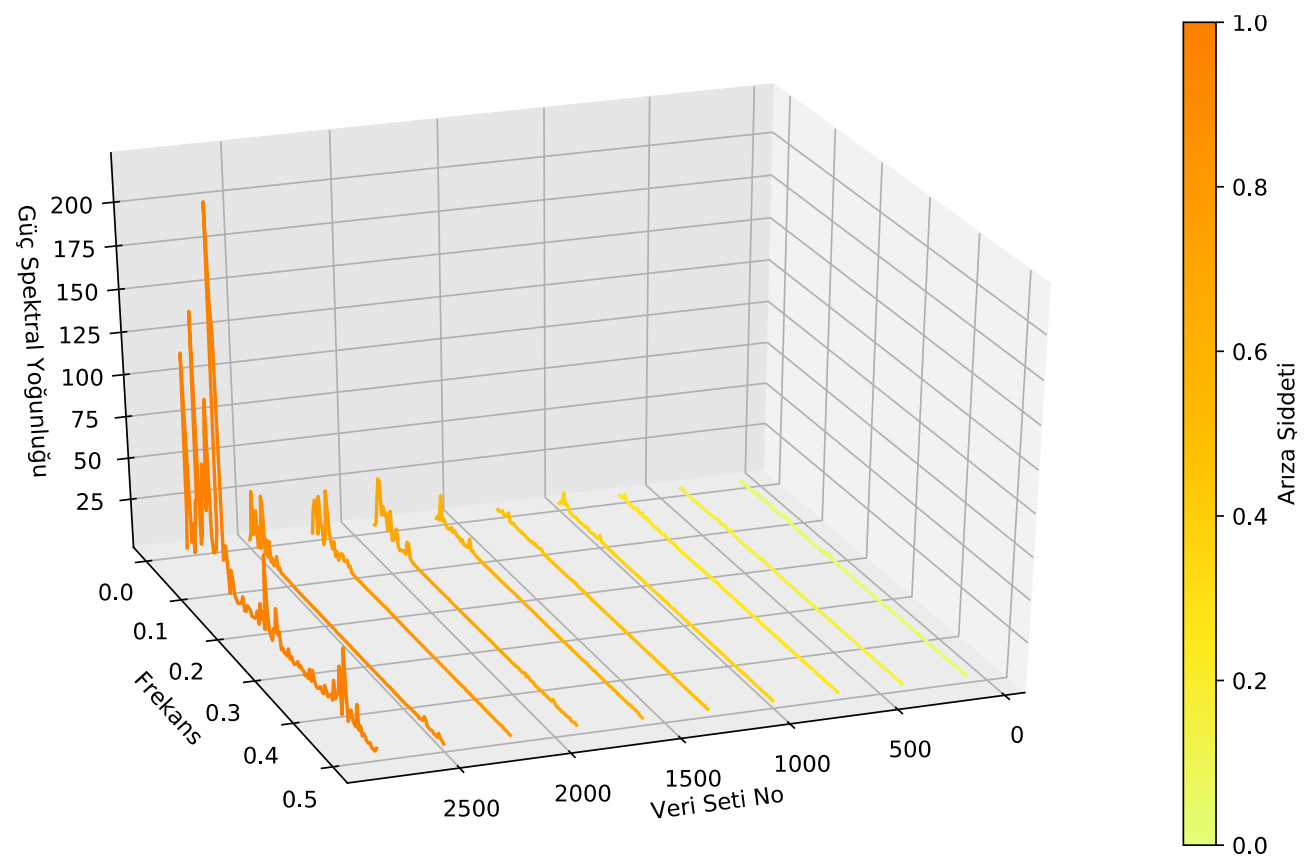

Şekil 6 Güç Spektral Yoğunluğu (Aralıklı Gösterim)

Alt veri setlerinden alınan her bir sonuç vektörünün maksimum değeri alınırsa Şekil 7-a'da görüleceği gibi bozulmayı temsil edecek bir eğriye ulaşılır. Önceki örneklerde belirtildiği üzere bitime yakın değerlerde yüksek bir artış gözlemlenmektedir. Yine bu kısımlar arındırılıp Şekil 7-b'de olduğu üzere gösterildiğinde, eksponansiyel artış karakteristiği gösteren bozulma eğrisi daha açık bir biçimde 
gözükmektedir. Buradaki tanımlayıcı grafik, erken aşamaların belirgin bir şekilde küçük bozulma büyüklüğüne ve operasyon sonuna doğru olan aşamaların ise artan bir bozulma değerine sahip olduğunu göstermektedir. Artan ölçekte, daha yüksek skorlar operasyonda çarpıcı bir anormallik olduğunu göstermektedir. Dolayısıyla bu tanımlayıcı değerler, beklendiği üzere döner mekanizma sisteminin yükselerek artan bir bozulmaya sahip olduğunu ispatlamaktadır.

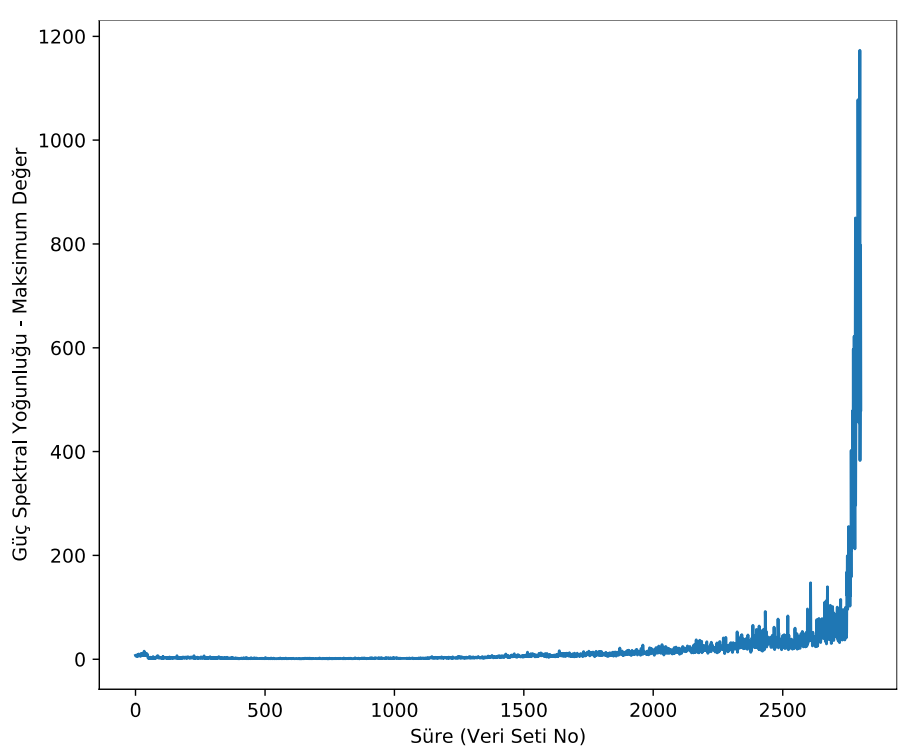

Şekil 7- a) Maksimum Değer

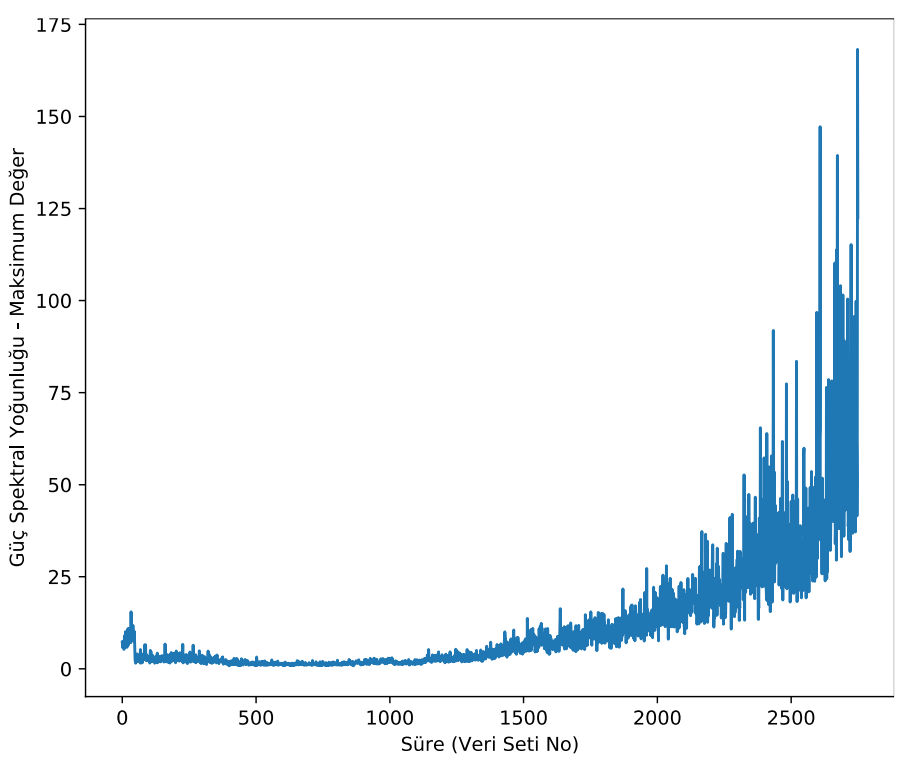

Şekil 7- b) Maksimum Dĕ̌ger (Klsmi)

Sistemlerden alınan sinyallerde genel olarak görüldüğü üzere, bu grafikler de gürültü olarak adlandırılan büyük miktarda ek anlamsız bilgiye sahiptir. Bu gürültülü veriler analizin sonuçlarını olumsuz olarak etkileyebileceği ve düzgün olarak ele alınmadığ durumda sonuçların sapmasına neden olacağı için, verilerin gürültüsünü ayıklamak amacıyla Şekil 8- a'da görüleceği üzere "Hareketli Ortalama" yöntemi uygulanmıştır. Burada pencere içinde kalan veriler $p_{1}, \ldots, p_{n}$ şeklinde düşünüldüğünde ortalama Denk. 9 ve 10 'da sunulan şekilde formüle edilir

$$
\begin{aligned}
\bar{p}_{H O} & =\frac{p_{1}+p_{2}+p_{3}+\cdots+p_{n}}{n} \\
\bar{p}_{H O} & =\frac{1}{n} \sum_{i=1}^{n} p_{i}
\end{aligned}
$$

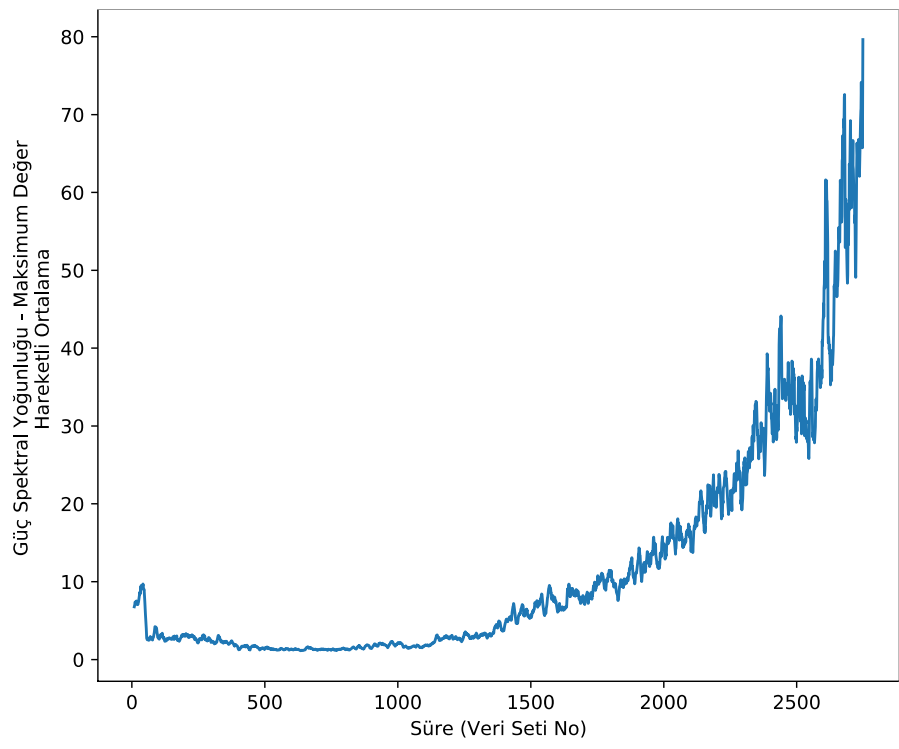

Şekil 8- a) Hareketli Ortalama - Bozulma Gösterim

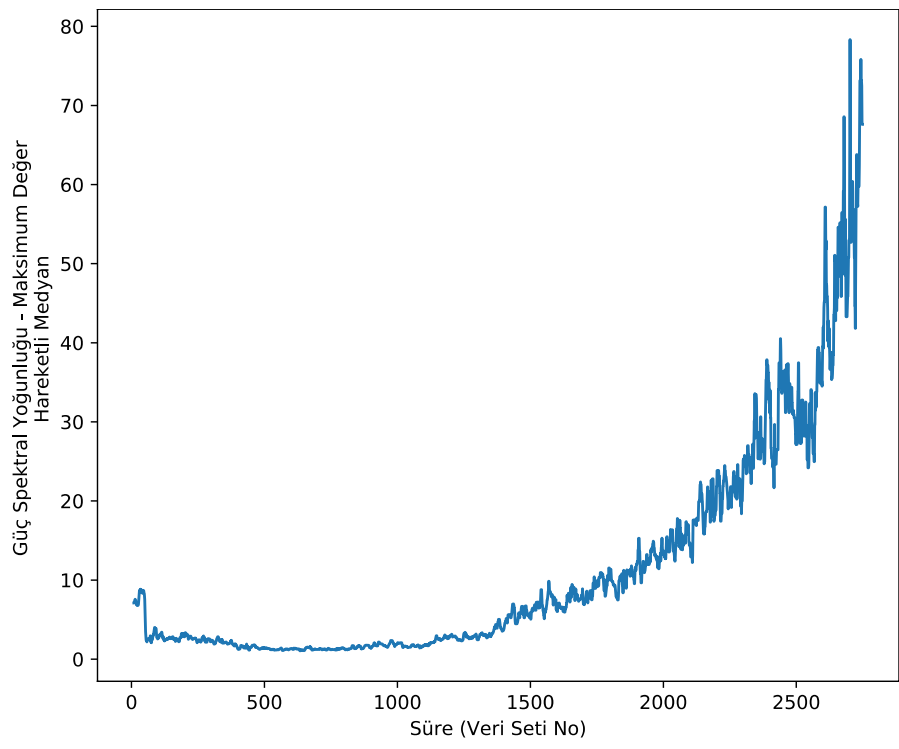

Şekil 8- b) Hareketli Medyan - Bozulma Gösterim

Şekil 8-b'de ayrıca medyan ortalama ile gösterim yapılmıştır (bknz Denk. 11). 


$$
\tilde{p}_{H M}=\operatorname{Median}\left(p_{1}+p_{2}+p_{3}+\cdots+p_{n}\right)
$$

Hem "Hareketli Ortalama" hem de "Hareketli Medyan" yöntemlerinde 10 adımlı bir pencere boyutu kullanılmıştır (n=10). İki şekil arasındaki fark bu çalışma açısından kayda değer olmayacak şekilde az olarak gözükse de ilerde faydalı ömür tahminlerinde iki farklı uygulamanın önemli farkları olabileceğinin altı çizilmelidir.

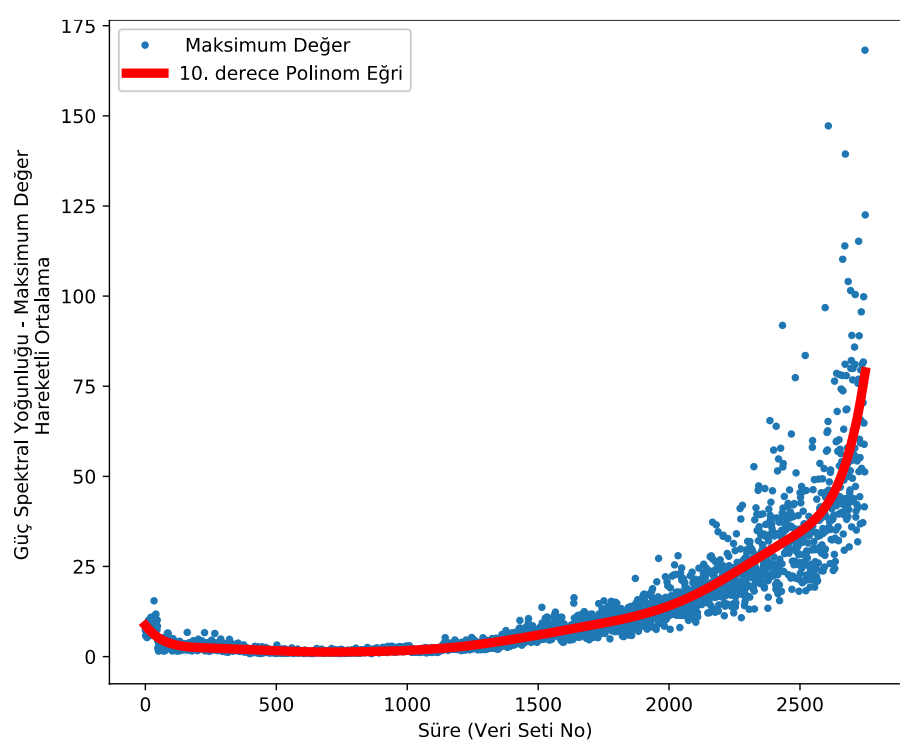

Şekil 9- a) Maksimum Değer (Kısmi) Bozulma Gösterim Polinom Ĕgrisi

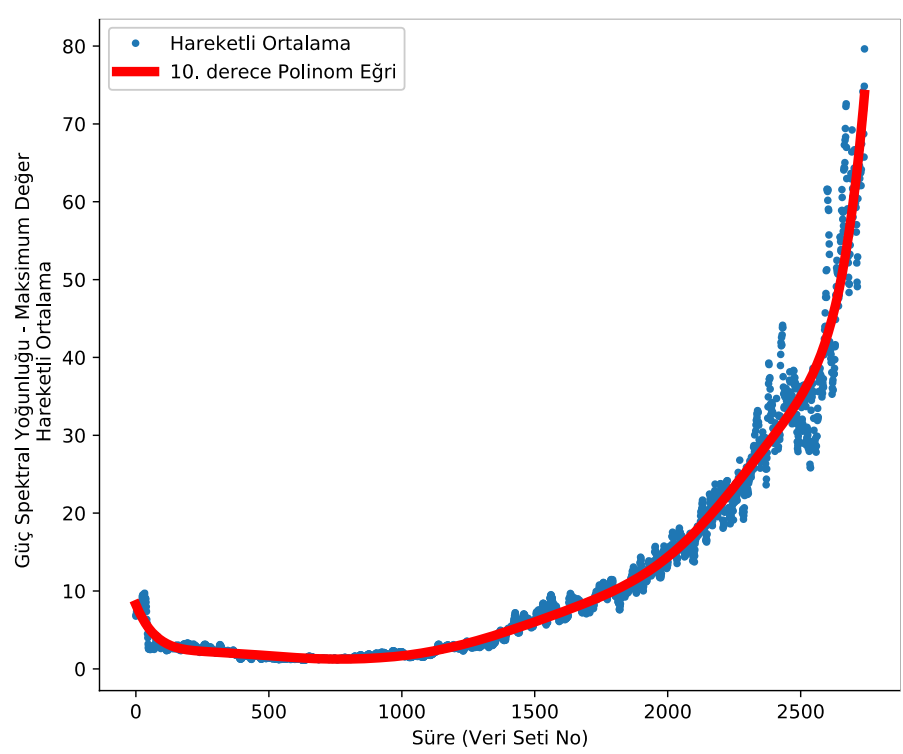

Şekil 9- b) Hareketli Ortalama Bozulma Gösterim

Polinom Ĕgrisi

Son olarak çalışma bozulma aşamalarını daha düzgün olarak göstermek amacıyla 10. dereceden polinom eğri uydurma yöntemi uygulanmıştır (bknz Şekil 9 a ve b). Buradaki regresyon analizinin amacı, bağımlı olan bir çıktı değerini, bağımsız bir değişkenin veya değişkenler vektörünün girdi değeri açısından modellenmesidir. Genel olarak, beklenen bu bağımsız değişkenin değeri $n$. dereceden polinom olarak Denk. 12'de verilen biçimde modellenebilir.

$$
y=\beta_{0}+\beta_{1} x+\beta_{2} x^{2}+\beta_{3} x^{3}+\cdots+\beta_{n} x^{n}+\varepsilon
$$

Polinom eğrisi için çözümleme yapılırken, karesel hata en aza indirilir. Sonuçlar, özellikle örneklemde olduğu gibi polinom derecesini yükselterek veya değiştirerek iyileştirilebilir. Burada sağlanan eğri bozulmanın daha iyi gözlemlenebilmesi için sağlanmışıtır. Alternatif eğri uydurma yöntemleri, kullanılan hayat yönetimi ve tahmini yöntemlerinin uygulanması ve çeşitliliğine göre farklılık gösterebilir. Bu nedenle, bu kısım sadece görsel bir sunum sağlama ve eğri uydurmanın ileride uygulanabilecek çalışmalarda uyumluluğunu göstermek amaciyla verilmiştir.

Elde edilen bulgular, titreşimin kabul alanının sınırlarını göstermek için bir "eşik değeri” ima edebilir. Böyle bir bölge, sıfır hipotezinin (null hypothesis) reddedilmediği titreşim analizinden elde edilen bir değer olarak kabul edilebilir. Bu kabul bölgesine bağlı olarak, kritik değerin aşıldığı durumlarda, operasyon sonlandırılabilir ve gerekli bakım, onarım işlemleri yapılabilir.

\section{Sonuç}

Bu çalışmada kestirimci bakımda kullanılmak üzere bozulma eğrisinin bulunması amaçlanmıştır. Arıza artış aşamalarının tanımlanması için uygulanan Welch yöntemiyle bozulmayı temsil edecek güç spektral yoğunluğu bulunmuştur. Sonrasında her bir alt veriden hesap edilen maksimum değerler ile bozulma eğrisi için veri noktaları elde edilmiştir. Bu makalede, havacılık gibi karmaşık sektörlerin gün geçtikçe artan titreşim verişi işleme ihtiyacına, durum izleme verilerini başarılı bir şekilde analiz ederek karşılık verilmiştir. Çalışma döner mekanizma ve benzer şekilde titreşim üreten sistemlerde durum verileriyle bozulmanın tamamlanabileceğini göstermektedir. Bundan ötürü, öne sürülen uygulamalar kestirimci bakım için önemli bir potansiyele sahip olup ve kullanışlı hayat analizi için devam çalışmalarına olanak sağlamaktadırlar.

\section{Kaynakça}

Heng, A., Zhang, S., Tan, C., A., \& Mathew, J. (2009). Rotating machinery prognostics: State of the art, challenges and opportunities. Mechanical systems and signal processing, 23(3), 724-739. 
Hong, S., Wang, B., Li, G., \& Hong, Q. (2014). Performance degradation assessment for bearing based on ensemble empirical mode decomposition and gaussian mixture model . Journal of Vibration and Acoustics, 136(6).

Hong, S., Zhou, Z., Zio, E., \& Hong, K. (2014). Condition assessment for the performance degradation of bearing based on a combinatorial feature extraction method. Digital Signal Processing, 27, 159-166.

Hu, C., Youn, B. D., Wang, P., \& Yoon, J. T. (2012). Ensemble of data-driven prognostic algorithms for robust prediction of remaining useful life. Reliability Engineering \& System Safety, 103, 120-135.

Lei, Y., Lin, J., He, Z., \& Zuo, M. J. (2013). A review on empirical mode decomposition in fault diagnosis of rotating machinery. Mechanical systems and signal processing, 35(1-2), 108-126.

Lei, Y., Lin, J., Zuo, M. J., \& He, Z. (2014). Condition monitoring and fault diagnosis of planetary gearboxes: A review. Measurement, 48, 292-305.

Mayer-Schönberger, V., \& Cukier, K. (2013). Big data: A revolution that will transform how we live, work, and think. Houghton Mifflin Harcourt.

Mills, S., Lucas, S., Irakliotis, L., Rappa, M., Carlson, T., \& Perlowitz, B. (2012). Demystifying big data: a practical guide to transforming the business of government. Washington: TechAmerica Foundation.

Patrick, N., Rafael, G., \& Kamal, M. (2012). PRONOSTIA: an experimental platform for bearings accelerated life test. IEEE international conference on prognostics and health management, (s. 590).

Öztanır, O. (2018). Makine Öğrenmesi Kullanılarak Kestirimci Bakım. Yüksek Lisans Tezi, Hacettepe Üniversitesi Fen Bilimleri Enstitüsü.

Smith, J. O. (2011). Spectral audio signal processing. W3K publishing.

Welch, P. (1967). The use of fast Fourier transforms for the estimation of power spectra: A method based on time averaging over short modified periodograms. IEEE Transactions on audio and electroacoustics, 15(2), 70-73.

Yaman, G., \& Karadayı, H. M. (2014). Titreşim analizi ile pompalarda arıza tesbiti ve kestirimci bakım için örnek bir çalışma. Tesisat Mühendisliği, 140, 37-51. 